\title{
The Analysis of Estee Lauder Group's Dominant Position Factors
}

\author{
Qianhui Sun ${ }^{1, a, \dagger}$, Jinghan Tang ${ }^{2, b, \dagger}$ and Zheshu Zhang ${ }^{3, c, \dagger}$ \\ ${ }^{1}$ International Business School, Dongbei University of Finance and Economics, Dalian 116025, \\ China \\ ${ }^{2}$ College of Literature, Science, and the Arts, University of Michigan, Ann Arbor, Ann Arbor MI \\ 48109, US
}

${ }^{3}$ Suzhou North America High School, No.268, Tian E Dang Road, Yuexi Town, Wuzhong District, Suzhou 215000, China

a1295227780@qq.com, bjinght@umich.edu, camonzzs@163.com

tThese authors contributed equally.

\begin{abstract}
This paper analyzes the factors that contribute to Estee Lauder's dominant position in the daily chemical industry. In this paper, we investigate the company's strategies, accountings, risk estimates and future prospects. In the strategy analysis, the 4P analysis method is adopted to analyze its advantages from the aspects of the price, place, promotion and product and the company's strategies under the COVID-19 pandemic. In accounting part, we have analyzed merging and acquisition, liquidity and efficiency of this company. We compare the debt-equity ratio, current ratio, quick ratio and turnover ratio to another company, Unilever, to analyze the advantages in accountings for Estee Lauder group. In the discussion part, this paper analyzes the risks faced by Estee Lauder group based on the real case, and makes an analysis of the future development prospects. This paper finds that Estee Lauder can remain invincible in the competition mainly due to its accurate market segmentation and effective financing strategies such as merger and acquisition of other companies. Through the analysis of Estee Lauder's competitive advantage, this paper provides some ideas for other small enterprises in decision-making and marketing.
\end{abstract}

Keywords: Mergers and acquisitions; 4P analysis; business model; risk analysis; Estee Lauder; and accounting ratios.

\section{Introduction}

The personal products sector of the consumer goods industry includes manufacturers of personal and beauty care products, which belong to consumer staples. Daily use chemicals are technology chemicals that people commonly use on a daily basis including shampoo, body wash, skin care, hair care, cosmetics, etc. The improving quality of life, the positive effects of beauty and personal care on self-esteem and social interaction, and the gradual consumer shift toward premium and luxury cosmetic brands are a few factors that are likely to propel the market growth during the forecast period. The global beauty and personal care market is highly competitive, with a strong presence of regional and global players in the market, where demand is mostly driven by more adaptation toward skincare routines and consumer awareness about brand know-hows. The most active companies in the market include key players, like Unilever, The Estée Lauder Inc and Coty. We choose to analyze The Estée Lauder Inc.

Estee Lauder began in 1946 with a \$50,000 investment by Mrs. Lauder and her husband, Newseur Lauder. It was a very small company, and its products consisted only of cleansing oils, creams, moisturizers, and all-over moisturizing serums [1]. When the revolutionary Youth Dew perfume was launched in 1953, the Estee Lauder brand earned a reputation for its constant pursuit of innovation, research and development, and superior quality. Today, the Estée Lauder Group is a world leader in the cosmetics industry, producing and marketing high-quality skin care, makeup, fragrance and hair care products that are sold in more than 130 countries around the world. Through the years, the Estée Lauder Group has built a family of brands with a unique balance. This balance 
is reflected in the positioning of all the brands owned, in the different consumer groups to which they appeal, and in the balance of their strengths in terms of category and geography. The company has many well-known brands, including Estee Lauder, Aramis, Clinique, Perscriptives, Origins, MAC, LA MER, etc [2]. Estee Lauder has had numerous innovations and creations since its birth. For example, the marketing techniques that have now been commonly adopted by many cosmetic brands: product trials, gift-giving with purchases, and promoting women to shop for their own fragrances were all first innovated by Estee Lauder. Estee Lauder's product style is refined in research and development and refined elegance, and its thematic products are skincare, color cosmetics and fragrance products. These cosmetic, skincare and fragrance products are suitable for oriental people. Estee Lauder products are sold at Estee Lauder counters in major cities across mainland China, including Beijing, Shanghai, Shenzhen, Guangzhou, Harbin, Changchun and Nanjing.

We firstly discussed Astrid's strategy, divided into corporate strategy, marketing strategy and strategy under the new crown epidemic. Secondly, the paper introduces the transaction theory, mentioning Estee Lauder's mergers and acquisitions, liquidity and efficiency. Finally, we analyze the potential risks of Estee Lauder in various aspects and make forecasts for the future.

\section{Strategies}

\subsection{Corporate Strategy}

Estée Lauder Group is one of the largest premium cosmetics multinational manufacturer and marketer over the world, whose success is based on its commitment of "bringing the best feeling to everyone we come in contact with". Notably, focusing on maintaining brand balance is a fundamental part of the company, which means both core and new brands of Estée Lauder were treated equally in the premium channel. In addition, the company not only focuses on new brands, but also emphasizes deepening existed brands, for instance, maintaining the integrity of classic products, inventing new categories of cosmetics, and developing new technologies in the manufacturing processes. Furthermore, Estée Lauder invested heavily and aggressively in marketing, including advertisement and commercial promotions, which ensures all the brands own their unique global images.

The development of Estee Lauder Group is also achieved by acquiring brands or companies containing business value, which means these brands already had their own market positions before the acquisition. Interestingly, Estée Lauder prefers to manage the acquired brands by respecting the independence of each brand to a considerable degree and developing their personalities. It pursues its own criteria when acquiring new brands or companies, which can create unique business opportunities. In addition, the group prefers to build up a complementary relationship instead of a weaken one with the existed brands of company [3].

\subsection{Market Strategy}

In this section, we use 4P to describe Estée Lauder Group's market strategy: Product, Price, Promotion and Place.

\subsubsection{Product Strategy}

Products play the most important role in the marketing mix. Thus, when customizing its marketing mix, the companies need to find out which products need to be produced that can meet the requirements of the target market. Estee Lauder group owns many famous brands under its umbrella in China, like Clinique and La Mer. For example, La Mer is a high-end brand that targets young to middle-aged women over the age of 25 and has a certain income; Clinique targets younger women between the ages of sixteen and twenty-five, and has a price advantage. 


\subsubsection{Price Strategy}

Price competition is a valuable tool in marketing activities. Commonly, Estee Lauder determined product prices according to the strategy that was based on the understanding of consumers regards to the product value and market demand level. In addition, Estee Lauder used prestige pricing strategy and product range pricing strategy. The prestige pricing strategy maintained the high prices of products, while the product range pricing is a type of product mix pricing strategies. In detail, Estee Lauder always combined together the products with approximate prices as product sets, and then determined an overall price to sell the sets.

\subsubsection{Promotion Strategy}

The development of Estee Lauder in China was mainly depended on the precise advertising direction. When Estee Lauder entered the market of China, it concentrically advertised in fashion magazines, which directly showed the qualities and characteristics of products, and easily attracted the attention of readers. The main consumer groups of Estee Lauder were female professionals with high income and the so called new women who pursued fashion. Presently, Estee Lauder also shifted the concentration of promotion on TV commercials, which exhibited the products with sounds and colors, and spread the influence of promotion widely. As mentioned before, the main consumers of Estee Lauder are women, and typically they are easily seduced by beauty. Therefore, the effect of promotion on TV commercials is more significant than the conventional channels, which can widely increase the popularity of products and enhanced the purchase desire of public. Utilizing the celebrity effect is another promotion strategy of Estee Lauder, for example, the advertisements of Estee Lauder always chose models or celebrities as spokespersons. In brief, all the promotion strategies of Estee Lauder significantly increased the sales of products.

\subsubsection{Place Strategy}

The selling channels of Estée Lauder were controlled to limited number in order to maintain the high-level of product positions, which contained exclusive department stores, high-end perfume stores, professional beauty parlour, duty-free shops in airports, and web-stores.

\subsection{Strategy under the New Crown Epidemic}

The COIVD-19 has brought Estee Lauder Group's hot streak to an urgent juncture. Estée Lauder Group noted that retail stores in most markets around the world were temporarily closed due to the outbreak. In addition, the sharp drop in flights has hit travel retail. Turnover declined in the Americas, Europe, Middle East and Africa, but Asia Pacific remained positively profitable. During this period, most of the Group's factories were still producing and distributing merchandise, despite the significant decline in capacity. In response to the impact of the new epidemic, Estée Lauder announced a "post-epidemic plan". One of the key elements of the plan is the layoff of staff and the closure of physical sales stores. The company currently estimates a net reduction of approximately 1,500 to 2,000 jobs worldwide and will close $10-15 \%$ of its freestanding stores in the U.S. and European markets.

Estee Lauder is paying more attention on its skin care products, which remain the fastest growing speed in the beauty market. However, it not means Estee Lauder is ready to give up the cosmetics, but searches more innovations to digest the sluggish sales in the category. A study found that much business is now conducted online, and many beauty industries experienced growth of 20 to $30 \%$ in online revenue during COVID-19. To keep advance, Estée Lauder quickly changed the method of delivering services to consumers. In-store beauty consultants of Estee Lauder have also shifted to social selling in order to continue promoting products at home. For example, numbers of work has been done to ensure La Mer can contact all the loyal consumers in China to find whether they wished to refill any products at home. Therefore, they have achieved the goal of reducing customer churn rate. 


\section{Accounting}

\subsection{Trade-off Theory}

Trade-off Theory is a business model that involves offsetting the costs of debt against the benefits of debt. Trade-off Theory states that the cost of debt should be always be lower than the cost of equity as the tax can be deducted from the interest paid on debt. Estee Lauder has a very high leverage in the perspective of tax shield. Due to the tax shield, Estee Lauder therefore could reduce their debt. Estee Lauder group needs to consider about how much debt they can afford. If they consider about this element, they may save taxes from the reasons of debt.

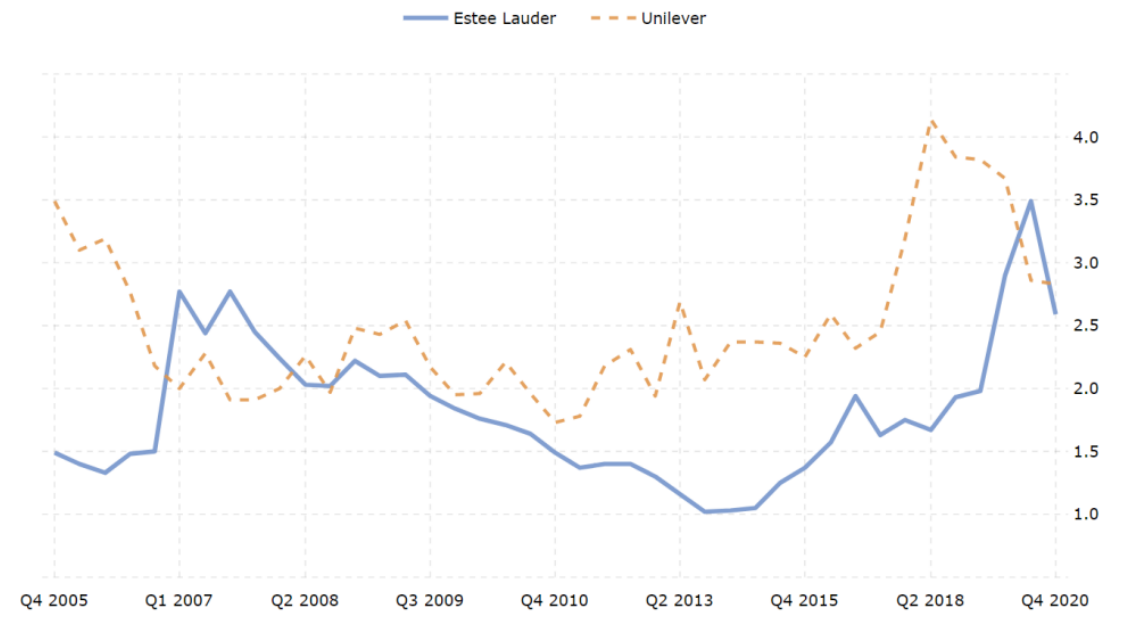

Fig. 1 Comparison of debt equity ratio of Estee Lauder and Unilever[6]

In this research, we used Unilever as an example to compare with Estee Lauder group. (The chart above [Figure 1] shows the comparison of debt equity ratio of these two companies) In this chart, it is obviously to know that for most of the time, the debt equity ratio of Estee Lauder is smaller than Unilever's. After reviewing the data of these two companies, we found that the thing Estee Lauder group should deserve is to raise their debt ratio in order to save taxes.

According to trade-off theory, Estee Lauder should avoid the huge amount of taxes, lower the agency costs occurring by the conflicts between shareholders and managers benefits and also increase the costs of financial distress and bankruptcy [4].

\subsection{Mergers and Acquisitions}

After the acquisition of Becca Cosmetics, a company that was merged by Estee Lauder in 2016, Estee Lauder Companies acquired Too Faced Cosmetics for $\$ 1.45$ billion, which was the largest acquisition in the company's history in December 2016. This transaction would bring in about 5.4 times of the revenue for Too Faced Cosmetics. This act of acquisition had raised Estee Lauder's profile in prestige daily chemical industry. After the acquisition, Estee Lauder announced they will keep tracking with the opportunities to merge and acquisition.

Estee Lauder continued merging the companies to get more benefits after the acquisition of Too Faced Cosmetics. In June 2017, Estee Lauder first invested in Deciem [5], and it bought a 29\% stake in the company, according to public filings. In February 2021, Estee Lauder Companies announced the official statement that they invested an additional $\$ 1$ billion in Canadian beauty company Deciem, increasing its stake in the company from $29 \%$ to $76 \%$. Estee Lauder states this is the first stage of full acquisition of the company by group, which will be completed within 3 years. This transaction valued Deciem at $\$ 2.2$ billion. This time of acquisition has become a larger acquisition than the one for Too Faced Cosmetics. 


\subsection{Liquidity and Efficiency}

From liquidity perspective, the current ratio of Estee Lauder we have calculated in 2021 Q1 is 1.72 , which indicates a good current ratio. In this case, the company could have more than enough cash to service its debt and use its capital efficiently. Compared the current ratio to Unilever we have selected as an example, which about 0.73, Estee Lauder Companies show a better ability on paying short-term obligations than Unilever. The quick ratio for Estee Lauder is 1.32, which means the company should not have any trouble when paying the short-term debts.

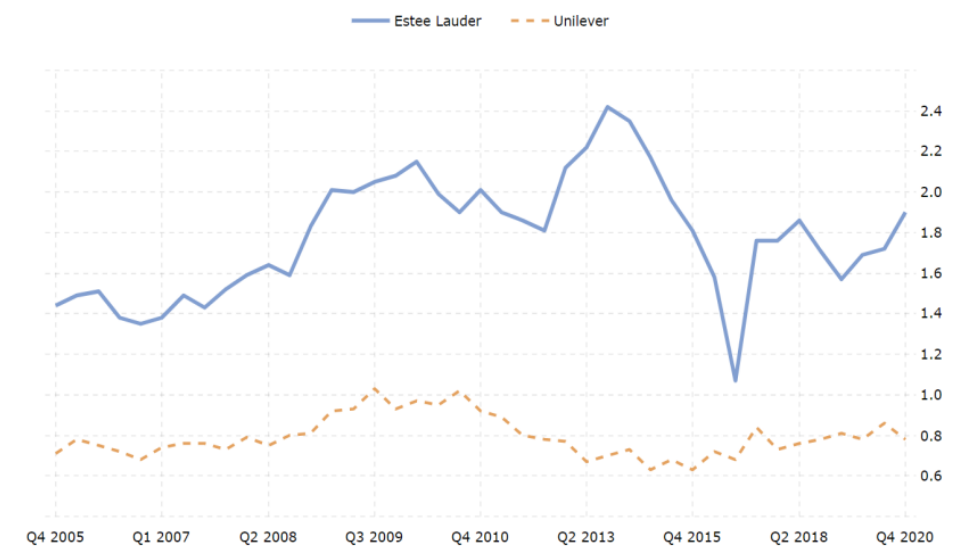

Fig. 2 Comparison of current ratio of Estee Lauder and Unilever [6]

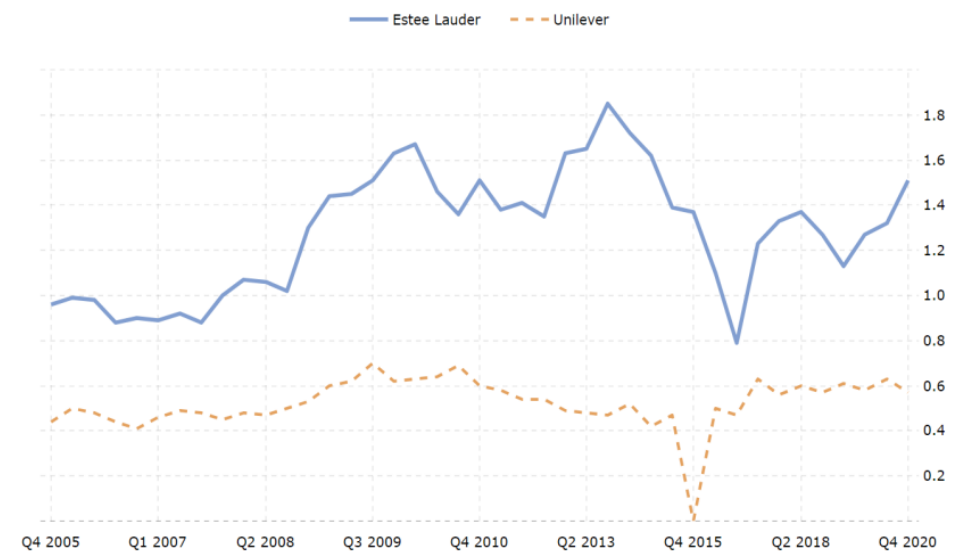

Fig. 3 Comparison of quick ratio of Estee Lauder and Unilever [6]

The upper chart [Figure 2] shows the comparison of current ratio of Estee Lauder and Unilever [6], while the lower chart [Figure 3] shows the comparison of quick ratio of these two companies. In both of these two charts, we could notice that Estee Lauder have a much higher current ratio and quick ratio than Unilever. Therefore, it is clear for us to know that in the select range of years, Estee Lauder group has a much better situation on paying short-term obligations than Unilever.

Estee Lauder has a total asset turnover ratio of 0.92 from the efficiency perspective. As we can see, Estee Lauder therefore does not have a good asset turnover ratio. The total asset turnover ratio is less than 1, which means Estee Lauder's total assets may not able to produce enough revenue at the end of the year [7]. Unilever, however, only owns a total asset turnover ratio about 0.06 , which means it's much lower than the ratio of Estee Lauder. The greater the total asset turnover, the better the efficiency of the company. A good asset turnover ratio should be about 2.5 or more. 


\section{Discussion}

\subsection{Risk of Customer Trust Crisis}

Consumer trust and loyalty affects the product market dramatically. [8] According to the data report of Thailand tourism industry, customer trust and loyalty have a significant positive impact on the willingness to purchase local products again (Laparojkit and Suttipun, 2021). Recently, [9] Estee Lauder (Shanghai) Trading Co., Ltd. added a new administrative penalty and was punished for false or misleading business propaganda, the penalty content was a fine of 400,000 yuan. Besides, it was ordered to stop illegal behavior, while this was not the first time. Estee Lauder has been punished because of similar problems. Many netizens said that a mere 400,000 yuan fine for big cosmetics companies is hardly a lesson. Some netizens even calculated a sum of account: an Estee Lauder small brown bottle costs 1150 yuan, the monthly sales of 60,000 bottles, 400,000 yuan about 348 bottles. The fine was relatively small, but the Twitter hashtag Estee Lauder was fined 400,000 for false publicity and has been viewed more than 300 million times, even though it was two of Estee Lauder's brands that were punished, many netizens have already complained about other brands and products of Estee Lauder under the topic (Wang, 2021).

This is an example of Estee Lauder facing a crisis of consumer confidence and the corporation increased the risk of losing customers as a result of this misbehavior. To solve the crisis of consumer trust and reduce the risk of customer loss, Estee Lauder must take appropriate measures to attract customers. It is because of false advertising and excessive marketing that the enterprise not only lost 400,000 yuan but also damaged the image of the enterprise. Therefore, achieving authenticity is the main goal of the enterprise. Estee Lauder should pay attention to the quality of the product and the most important thing is that the real product should match the quality of the product shown in the advertisement.

\subsection{Price and Market Risk}

Price is a very sensitive factor that difficult to control in the marketing mix, which is directly related to the acceptance of products that are produced by the market, affects the market demand, and the profits of enterprises and involves the interests of producers, operators, and consumers. At the time of pricing, the enterprise should make its objective clear at the present stage, which is to maintain survival, maximize current profit, maximize market share, or optimize product quality. [10] Zhuang, Leszczyc and Lin (2018) pointed out that the price factor provides the most effective information for the product market. In the Chinese market, the price of an ordinary Estee Lauder lipstick is 230 yuan, and the price of a basic skincare product is about 600 yuan. As a luxury-goods maker, Estee Lauder faces the challenge of what prices consumers can afford, as the percentage of Chinese women who spend more than 500 yuan a month on cosmetics is still small. So Estee Lauder could follow the footsteps of its competitors L 'Oreal and Procter \& Gamble and cut prices when appropriate to break into the market. However, customers are a large and complex group and there are great differences in consumer psychology, buying habits, income level, geographical environment, and cultural environment. Therefore, different consumers and users have certain differences in their demands and purchasing behaviors for the same type of products.

Therefore, enterprises need to carry out market segmentation, selection and positioning. Estee Lauder products with its tradition, quality, innovation, fashion, diversity, wisdom, tolerance, and the responsibility of the brand concept to meet the wishes of many yuan noblewomen, and as a luxury manufacturer, Estee Lauder has never intended to lower the price. Therefore, the customer group it faces can be positioned as middle and high-income women.

Furthermore, according to the different regions and age groups, differentiated marketing strategies can be used for marketing, such as 20-year-old women are most worried about blackheads, 30-year-old women are most worried about dark yellow skin, and 40-year-old women are most worried about wrinkles; The skin of northeast women is fair but slightly rough, with redness and dullness. The skin of southeast women is fair and delicate. 


\subsection{Competitor Risk}

Competitor risk plays a significant role in market in cosmetics market. [11] Kim and Reinschmidt (2011) indicated that the outcome of competition depends on the risk behavior of competitors, which in turn is affected by the attitude of the organization to risk. The behavior of competitors is crucial in the process of risk management. Take the Chinese market as an example, in recent years, advocating domestic products has become a mainstream trend that cannot be ignored by Chinese consumers. A growing number of consumers are turning away from international luxury brands like Estee Lauder and supporting the growth of China's homegrown cosmetics industry. The main body of cosmetics production and management in China is on the rise. In 2014, there were 4,316 cosmetic enterprises in China, and by the end of November 2018, there were 4,664 cosmetic manufacturers. Driven by strong consumer demand and national policies, cosmetics import volume and import amount continue to increase in recent years. In the first half of 2019, 105,900 tons of beauty cosmetics and skincare products, up 19.2\% year-on-year. Imports amounted to the US $\$ 4.135$ billion, up $46.5 \%$ year on year. Meanwhile, China's cosmetics exports continue to increase. In 2018, China exported 208,800 tons of beauty cosmetics and skincare products, up $15.6 \%$ year on year. The export value was $\$ 2.469$ billion, up $21.5 \%$ year on year. In the first half of 2019, the export volume and value of China's beauty cosmetics and skincare products both increased. In terms of market share, Chinese cosmetics brands have accounted for $56 \%$ of the market share. Domestic cosmetics brands mainly focus on the low-end market, while overseas and joint venture brands mainly occupy the high-end market.

Therefore, if Estee Lauder wants to maintain its brand advantage, it needs to take the high-end market as its main market and maintain its image as a high-end brand. Despite the gradual rise of the daily chemical industry, people are still more willing to trust international brands with a certain historical background in skincare products

\section{Conclusion}

Estee Lauder as a long history of the daily chemical brands, has established a profound brand culture and consumer base. As can be seen from the above analysis, Estee Lauder was able to maintain stability in the face of the impact of such extreme conditions as the epidemic and did not suffer fatal trauma like some brands. Precise consumer group positioning, market segmentation, excellent product research and development, perfect sales strategy, a long history of brand culture and philosophy, are the guarantee of Estee Lauder's sustainable development. In addition to its conditions, the daily chemical market is also more and more attention. Although increased competition will bring great challenges to Estee Lauder, more opportunities.

As COVID-19 has impacted the world a lot, Estee Lauder Companies also suffer a lot from the pandemic. The group has donated a lot of either money or materials since the start of the pandemic. Due to the COVID-19 directive, most of London's retail stores in the Americas and Europe have been closed since mid-March in 2020 whether operated by the company or its customers. As the air travel continues to decrease significantly, the COVID-19 primarily affected the company's travel retailing business. In financial aspect, Estee Lauder group has improved financial flexibility and liquidity due to the effects of COVID-19. In the second quarter of 2021, the net sales increased from the previous quarter despite setbacks caused by the COVID-19 pandemic. For the current fiscal year, Estee Lauder expects to maintain in growth and continue achieve sequential sales growth. The company sets their plan to return to its long-term sales growth targets of $6 \%$ to $8 \%$. In addition, they expect a 50 basis point increase in operating margin and double-digit growth in adjusted amortized earnings per share in constant currency after the pandemic recovery period. In addition, reputation theory plays a significant role in the development of an enterprise. Piñeiro-Chousa, Vizcaíno-González and López-Cabarcos (2016) indicated that, if entrepreneurs think that reputation is a source of risk, analysis will be built into a prisoner's dilemma model, through the prevention from the reputation of the enterprise sustainability threatened to solve this 
problem Second, if entrepreneurs believe that reputation is a competitive advantage, and analysis was framed as the innovator's dilemma, won a high reputation from the entrepreneurial support opportunities to solve. In terms of the Estee Lauders, its reputation influences the consumers' choice dramatically and should be a competitive advantage. As a well-known brand in the cosmetics industry, the Estee Lauder's reputation appeals to a large number of consumers to buy cosmetics and skin care products. Generally, the social group focuses on the comments of the luxury even rather than their quality. Nevertheless, product quality determines the reputation. Only by ensuring the quality of products, continuous innovation, and creating healthier, more effective and more efficient cosmetics can the reputation be guaranteed. This would also be an emphasis of the strategy of the Estee Lauders in the future.

\section{References}

[1] The estée story. - The Estée Lauder Companies Inc. (2017, July 25). Retrieved October 6, 2021, from https://www.elcompanies.com/en/who-we-are/the-lauder-family/the-estee-story.

[2] Our brands. - The Estée Lauder Companies Inc. (n.d.). Retrieved October 6, 2021, from https://www.elcompanies.com/en/our-brands.

[3] Team, T. (2015, October 7). Why acquisitions could be the key for Estee Lauder. Forbes. Retrieved October 6, 2021, from https://www.forbes.com/sites/greatspeculations/2015/10/07/why-acquisitionscould-be-the-key-for-estee-lauder/?sh=61c1ffa17a48.

[4] Hackbarth, D., Hennessy, C. A., \& Leland, H. E. (2007). Can the trade-off theory explain debt structure? Review of Financial Studies, 20(5), 1389-1428. https://doi.org/10.1093/revfin/hhl047

[5] Yakhontova, T., \& Ivantsiv, O. (2021). "we are strong believers in the power of the Avon Brand": Genre features of International Cosmetics Companies' e-releases. ESP Today, 9 (2), 182-205. https://doi.org/10.18485/esptoday.2021.9.2.1, pp.11

[6] Stock comparison tool. MacroTrends. (n.d.). Retrieved October 7, 2021, from https://www.macrotrends.net/stocks/stock-comparison?s=quick-ratio\&axis=single\&comp=EL.

[7] Graham, B., \& Meredith, S. B. (2007). The interpretation of financial statements. HarperBusiness. pp. $13-14$

[8] Kim, H., \& Reinschmidt, K.F. (2011). Effects of Contractors' Risk Attitude on Competition in Construction. Journal of Construction Engineering and Management-asce, 137, 275-283.

[9] Laparojkit, S., \& Suttipun, M. (2021). The Influence of Customer Trust and Loyalty on Repurchase Intention of Domestic Tourism: A Case Study in Thailand During COVID-19 Crisis. Journal of Asian Finance, Economics and Business, 8, 961-969.

[10] Wang, Y.B. (2021). Estee Lauder is fined 400,000 yuan for false propaganda. Why is it not banned again? National Business News, 1, 1-2.

[11] Zhuang, H., Leszczyc, P.T., \& Lin, Y. (2018). Why is Price Dispersion Higher Online than Offline? The Impact of Retailer Type and Shopping Risk on Price Dispersion. Journal of Retailing, 94, 136-153. 